\title{
Wpływ warunków temperaturowych otoczenia na wymianę ciepła w przemysłowych gazomierzach miechowych
}

\begin{abstract}
W artykule omówiono proces wymiany ciepła w przemysłowych gazomierzach miechowych i wpływ warunków atmosferycznych na to zjawisko. Potwierdzono, że wymiana ciepła pomiędzy otoczeniem przemysłowych gazomierzy miechowych a gazem płynącym w ich wnętrzu jest silnie zależna od powierzchni wymiany ciepła, jaką jest obudowa oraz od objętości cyklicznej. Wraz ze wzrostem wielkości gazomierzy miechowych wydłuża się droga dla przepływającego medium, a tym samym i czas oddziaływania temperatury otoczenia, co skutkuje pogłębieniem różnicy pomiędzy temperaturą gazu na wlocie i wylocie z gazomierza. Dalsza analiza pozwoliła na wytypowanie reprezentatywnego miejsca do pomiaru temperatury gazu w celach rozliczeniowych objętości zużytego gazu oraz na opracowanie zaleceń dla układów rozliczeniowych wykorzystujących przemysłowe gazomierze miechowe.
\end{abstract}

Słowa kluczowe: przemysłowe gazomierze miechowe, nierozliczone ilości gazu, proces wymiany ciepła, wpływ warunków atmosferycznych na temperaturę gazu, pomiar termowizyjny.

\section{Influence of ambient temperature on the heat transfer process in industrial diaphragm gas meters}

The article depicts the process of heat transfer in a diaphragm gas meter and the possible impact of weather conditions on this process. It has been confirmed that the heat exchange between the inner and outer temperatures of an industrial diaphragm gas meter, is dependent on the heat exchange surface such as the housing and the cyclic volume. Along with the increase of the gas meter's size, the path for the flowing medium extends, and hence the time of impact of the ambient temperature, which results in a widening of the difference between the inlet and outlet gas temperatures. Futher analysis allowed to identify a representative place to measure the temperature of the gas, for the purpose of billing the volume of gas consumed and to develop recommendations for billing systems that use industrial diaphragm gas meters.

Key words: industrial diaphragm gas meters, unsettled volume of gas, heat exchange process, impact of weather conditions on temperature of gas, thermovision.

\section{Wprowadzenie}

Gazomierze miechowe to najczęściej spotykany rodzaj gazomierzy wykorzystywanych do pomiarów gazu zarówno w zakładach produkcyjnych, jak i w indywidualnych gospodarstwach domowych [11].

Pomiar objętości gazu u odbiorców, u których sumaryczne maksymalne zużycie gazu przez wszystkie zainstalowanie urządzenia gazowe jest większe lub równe $10 \mathrm{~m}^{3} / \mathrm{h}$, dokonywany jest przez przemysłowe gazomierze miechowe. W niektórych krajach gazomierze miechowe są stopniowo zastępowane przez gazomierze ultradźwiękowe. Niemniej jednak nadal posiadają wiele zalet, m.in.: trwałość, długoterminowa stabilność metrologiczna, małe opory przepływu, odporność na wysoką temperaturę otoczenia $\left(650^{\circ} \mathrm{C}\right)$ przy jednoczesnym zachowaniu niskich kosztów produkcji $[8,20]$.

Pomiar wolumenu gazu dokonywany jest w określonych warunkach temperatury i ciśnienia gazu. Do celów rozliczeniowych objętość gazu zmierzoną w warunkach roboczych należy przeliczać do warunków odniesienia. Przeprowadzone przez specjalistów badania wykazały, 
iż domowy gazomierz miechowy jest dobrym wymiennikiem ciepła, stąd też na temperaturę w gazomierzu ma wpływ temperatura gazu na wejściu do gazomierza, która zależy w dużej mierze od temperatury gruntu panującej na głębokości ułożenia gazociągu, a także od temperatury otoczenia oraz strumienia przepływu w gazomierzu, który silnie wpływa na wzrost różnicy między temperaturą gazu a temperaturą otoczenia. Stosowanie niewłaściwych współczynników korekcyjnych temperatury w rozliczeniach gazu ziemnego powoduje, iż są one obarczone błędami, co przyczynia się do nierzetelności pomiarów rozliczeniowych $[1,7,12,17,21]$.

\section{Analiza przemysłowych gazomierzy miechowych na rynku rodzimym}

Dotychczasowe założenia dla domowych gazomierzy miechowych, zgodnie z którymi temperatura gazu w gazomierzu oraz temperatura otoczenia są niemal równe, nie mają zastosowania dla przemysłowych gazomierzy miechowych. Dzieje się tak m.in. ze względu na duży stosunek powierzchni obudowy zewnętrznej do powierzchni układu pomiarowego oraz wielkości strumieni objętości przemysłowych gazomierzy miechowych, z powodu interakcji pomiędzy strumieniem a temperaturą otoczenia i gazu wewnątrz gazomierza.

Poprzednie badania w tym zakresie $[5,13,15,16]$ przeprowadzone były w czasie, gdy różnorodność dostępnych gazomierzy na rynku była mniejsza, dlatego opracowane założenia dla jednego typu gazomierza mogły być adaptowane dla innych.

Obecnie producenci gazomierzy oferują szeroką gamę swoich wyrobów, stosując różne materiały czy też rozwiązania technologiczne do ich produkcji.

Dlatego jednym z kluczowych etapów pracy badawczej zrealizowanej w INiG - PIB była szczegółowa analiza przemysłowych gazomierzy miechowych dostępnych na polskim rynku i wytypowanie reprezentatywnych próbek do badań laboratoryjnych (tablica 1).

Ze względu na szeroką gamę poszczególnych typów gazomierzy miechowych (w każdej z wielkości dostępnych na rynku), zakres ich badań ograniczono do wielkości G6, G10 i G16.

Głównym kryterium wyboru odpowiednich próbek była koncepcja porównań opracowanego współczynnika $\Delta$. Współczynnik $\Delta$ określa stosunek pomiędzy powierzchnią obudowy gazomierza (która stanowi powierzchnię wymiany ciepła pomiędzy otoczeniem gazomierza a gazem płynącym w jego wnętrzu) a objętością cykliczną układu pomiarowego:

$$
\Delta=\frac{p}{V_{c}}\left[\frac{\mathrm{m}^{2}}{\mathrm{~m}^{3}}\right]
$$

gdzie:

$p$ - powierzchnia obudowy gazomierza, która stanowi powierzchnię wymiany ciepła pomiędzy temperaturą gazu $\mathrm{w}$ gazomierzu a temperaturą otoczenia $\left[\mathrm{m}^{2}\right]$,

$V_{c}$ - objętość cykliczna układu pomiarowego gazomierza [ $\left.\mathrm{m}^{3}\right]$.
Na podstawie szczegółowej analizy przemysłowych gazomierzy miechowych do badań laboratoryjnych starano się wytypować po jednym gazomierzu miechowym $\mathrm{z}$ danej wielkości, którego współczynnik $\Delta$ przyjmował wartość skrajną. Charakterystyki wybranych gazomierzy przedstawiono na fotografiach 1, 2 i 3 .

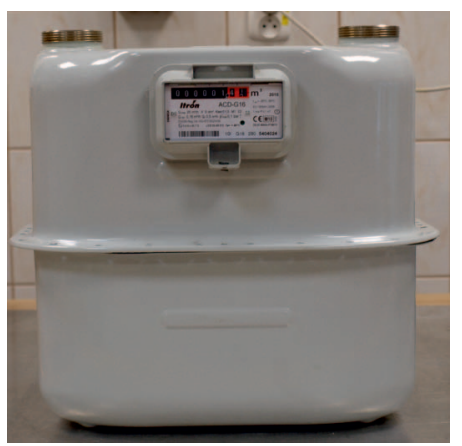

- producent: Itron

- wielkość: G16

- minimalny strumień objętości: $0,16 \mathrm{~m}^{3} / \mathrm{h}$

- maksymalny strumień objętości: 25,0 $\mathrm{m}^{3} / \mathrm{h}$

- objętość cykliczna: 5,0 dm $\mathrm{dm}^{3}$

- maksymalne ciśnienie pracy: $10 \mathrm{kPa}$

Fot. 1. Obiekt badawczy nr 1

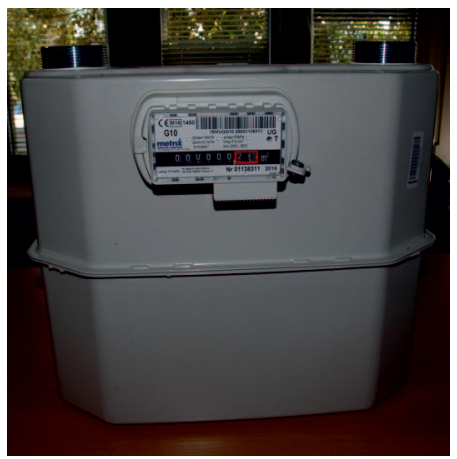

producent: APATOR METRIX

- wielkość: G10

- minimalny strumień objętości: $0,1 \mathrm{~m}^{3} / \mathrm{h}$

- maksymalny strumień objętości: $16,0 \mathrm{~m}^{3} / \mathrm{h}$

- objętość cykliczna: 5,6 $\mathrm{dm}^{3}$

- maksymalne ciśnienie pracy: $50 \mathrm{kPa}$

Fot. 2. Obiekt badawczy nr 2

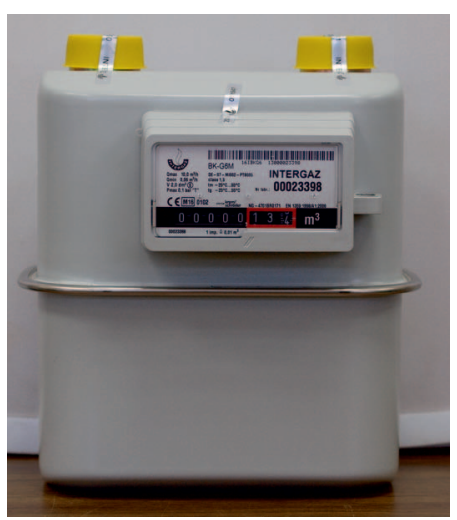

- producent: Intergaz

- wielkość: G6

- minimalny strumień objętości: $0,06 \mathrm{~m}^{3} / \mathrm{h}$

- maksymalny strumień objętości: $10,0 \mathrm{~m}^{3} / \mathrm{h}$

- objętość cykliczna: $2,0 \mathrm{dm}^{3}$

- maksymalne ciśnienie pracy: $10 \mathrm{kPa}$ 
Czujniki temperatury umieszczono w newralgicznych punktach gazomierza, wykorzystując właściwości symetryczne gazomierza miechowego i jednocześnie nie zakłócając jego prawidłowej pracy. Na rysunku 1 przedstawiono rozmieszczenie czujników temperatury w gazomierzu z oznaczeniami w celu identyfikacji miejsc zainstalowania, tj.:

- w króćcach wejściowym i wyjściowym gazomierza,

- w tulei sprzęgła magnetycznego.

- pomiędzy obudową gazomierza a układem pomiarowym,

- w układzie rozrządu gazomierza,

- w jednej z komór pomiarowych,

- na obudowie gazomierza pod liczydłem.

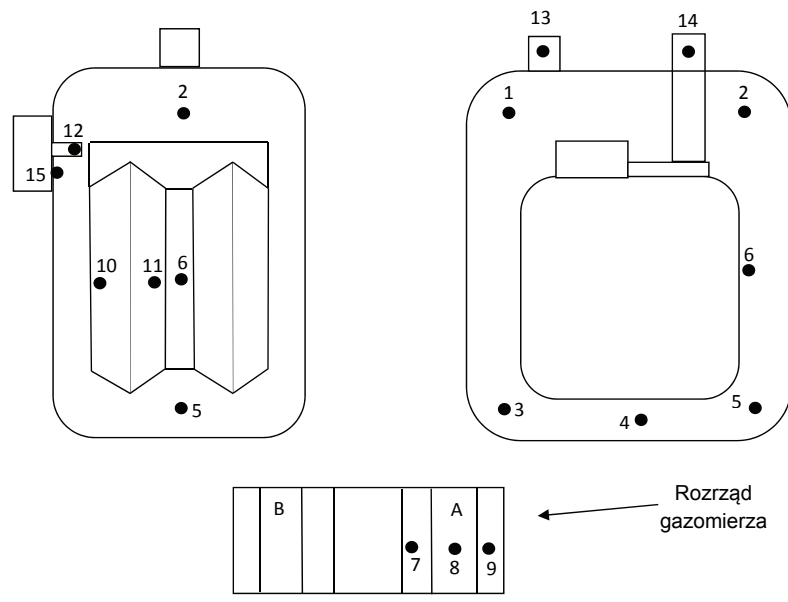

Rys. 1. Rozmieszczenie czujników temperatury w badanych gazomierzach

\section{Lokalizacja gazomierzy - nieodzowny element wpływający na temperaturę gazu w gazomierzu}

Zgodnie z ust. 1 i 2 § 166 rozporządzenia Ministra Infrastruktury w sprawie warunków technicznych, jakim powinny odpowiadać budynki i ich usytuowanie, $\mathrm{z}$ dnia 17 lipca 2015 r. [24], fundamentalnym wymaganiem jest oddzielne montowanie gazomierzy dla każdego odbiorcy, w miejscu zapewniającym łatwy dostęp do ich kontroli, konserwacji i wymiany, a także zabezpieczenie ich przed dostępem osób nieupoważnionych. Optymalnym miejscem do montażu liczników wraz z punktem gazowym są szafki gazowe, które należy montować na klatkach schodowych, korytarzach lub na zewnątrz budynku [6].

Ponadto $§ 168$ dokumentu [24] określa, iż gazomierze znajdujące się na zewnątrz należy montować w taki sposób, by ich spód znajdował się co najmniej $0,5 \mathrm{~m}$ nad poziomem terenu, ze względu na oddziaływanie czynników atmosferycznych (deszcz, śnieg).

Na podstawie przeprowadzonej analizy aktów prawnych [24] oraz doświadczenia eksploatacyjnego sieci i instalacji gazowych stwierdzono, że najczęstszą lokalizacją montażu gazomierzy są obecnie szafki gazowe w granicy działki.

Taka lokalizacja sprawia, iż gazomierz jest narażony na wpływ warunków atmosferycznych, a temperatura otoczenia zmienia się w skrajnych przypadkach od $-25^{\circ} \mathrm{C}$ do $55^{\circ} \mathrm{C}$. Dlatego w ramach niniejszej pracy zaprojektowano układ badawczy tak, by odzwierciedlał warunki rzeczywiste montażu gazomierza w szafce gazowej w granicy działki, z uwzględnieniem odpowiedniej długości i średnicy przyłącza gazowego.

Przyłącze gazowe z poziomu ułożenia (zgodnie z założeniami projektowymi jest to głębokość w zakresie $0,8 \div 1,1 \mathrm{~m}$ ) przechodzi pionowo przez płytsze warstwy gruntu aż na powierzchnię, łącząc się z armaturą redukcyjno-pomiarową.

Na podstawie przeprowadzonej analizy wymagań aktów prawnych [24], budowy technicznej szafek gazowych przezna- czonych do montażu gazomierzy G6, G10 i G16 dostępnych na polskim rynku, a także po konsultacjach z projektantami i wykonawcami przyłączy gazowych stwierdzono, że jeden metr jest najczęściej spotykaną długością fragmentu przyłącza gazowego wychodzącego spod powierzchni terenu i łączącego się z układem redukcyjno-pomiarowym (rysunek 2).

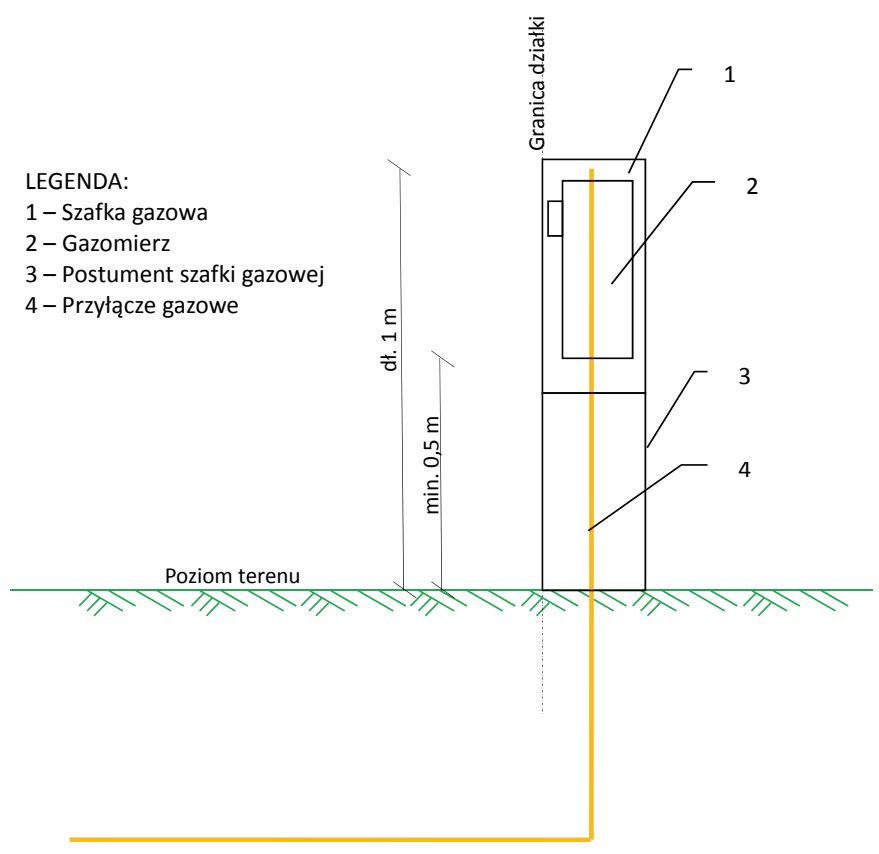

Rys. 2. Schemat przyłącza gazowego

Założenia projektowe pracy zakładały stworzenie układu odzwierciedlającego warunki rzeczywiste, gdzie przyłącze do punktu redukcyjnego będzie pracowało przy średnim ciśnieniu. Zgodnie z powyższymi założeniami i wymaganiami dotyczącymi maksymalnej prędkości przesyłu gazu w gazociągu oraz w oparciu o zalecenia Standardu Technicznego 
ST-IGG-1101:2011 Połaczenie PE/stal dla gazu ziemnego wraz ze stalowymi elementami do wtaczeń oraz elementami do przyłączeń [25], w których zostały zawarte dokładne wymagania co do stosowanych minimalnych grubości ścianek rur i kształtek gazociągów (tablica 1), obliczono maksymalną prędkość przepływu gazu w zależności od średnicy gazociągu i strumienia przepływu dla każdej z próbek badawczych (tablica 2).

W oparciu o otrzymane wyniki oraz racjonalność nakładów finansowych, które są ponoszone przy inwestycji budowy sieci gazowych, wytypowano do badań przyłącza o średnicy 3/4" dla gazomierzy G6 i G10 oraz 1" dla gazomierza G16 (fotografia 4).

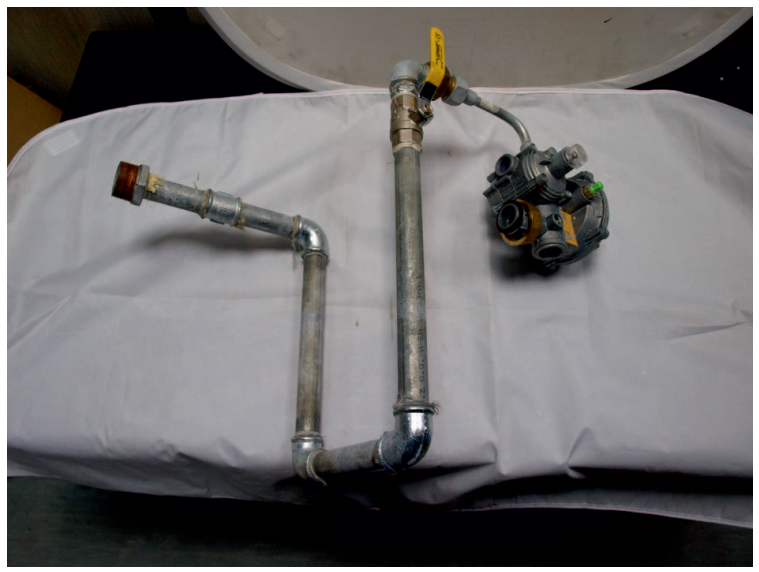

Fot. 4. Przyłącze wraz z reduktorem

Tablica 1. Minimalne grubości ścianek rur i kształtek według ST-IGG-1101:2011

\begin{tabular}{|l|r|r|r|r|r|r|r|r|r|}
\hline Średnica nominalna $D N[\mathrm{~mm}]$ & $\leq 25,0$ & 32,0 & 40,0 & 50,0 & 65,0 & 80,0 & 100,0 & 125,0 & 150,0 \\
\hline Średnica zewnętrzna $D z[\mathrm{~mm}]$ & 33,7 & 42,4 & 48,3 & 60,3 & 76,1 & 88,9 & 114,3 & 139,7 & 168,3 \\
\hline Grubość minimalna ścianki $g[\mathrm{~mm}]$ & 2,9 & 3,2 & 3,2 & 3,2 & 3,6 & 4,0 & 4,0 & 4,0 & 4,5 \\
\hline
\end{tabular}

Tablica 2. Obliczenia maksymalnej prędkości przepływu gazu w zależności od średnicy gazociągu i strumienia przepływu

\begin{tabular}{|c|c|c|c|c|c|c|}
\cline { 2 - 7 } \multicolumn{1}{c|}{} & Średnica & $d[\mathrm{~m}]$ & $F\left[\mathrm{~m}^{2}\right]$ & $Q\left[\mathrm{~m}^{3} / \mathrm{h}\right]$ & $Q\left[\mathrm{~m}^{3} / \mathrm{s}\right]$ & $v[\mathrm{~m} / \mathrm{s}]$ \\
\hline \multirow{3}{*}{$\mathrm{G} 6$} & $3 / 4$ & 0,0211 & 0,000349 & 10 & 0,002778 & 7,948093 \\
\cline { 2 - 7 } & 1 & 0,0279 & 0,000611 & 10 & 0,002778 & 4,545895 \\
\cline { 2 - 7 } & $5 / 4$ & 0,0360 & 0,001017 & 10 & 0,002778 & 2,730378 \\
\hline \multirow{3}{*}{ G10 } & $3 / 4$ & 0,0211 & 0,000349 & 16 & 0,004444 & 12,71695 \\
\cline { 2 - 7 } & 1 & 0,0279 & 0,000611 & 16 & 0,004444 & 7,273433 \\
\cline { 2 - 7 } & $5 / 4$ & 0,0360 & 0,001017 & 16 & 0,004444 & 4,368605 \\
\hline \multirow{3}{*}{ G16 } & $3 / 4$ & 0,0211 & 0,000349 & 25 & 0,006944 & 19,87023 \\
\cline { 2 - 7 } & 1 & 0,0279 & 0,000611 & 25 & 0,006944 & 11,36474 \\
\cline { 2 - 7 } & $5 / 4$ & 0,0360 & 0,001017 & 25 & 0,006944 & 6,825946 \\
\hline
\end{tabular}

\section{Program badań laboratoryjnych}

Badania laboratoryjne gazomierzy wyposażonych w czujniki temperatury przeprowadzono na specjalnie przygotowanym do tego celu stanowisku (rysunek 3).

Badany gazomierz z zamontowanymi czujnikami temperatury oraz przyłączem z punktem redukcyjnym został umieszczony w komorze klimatycznej, której zadaniem było zapewnienie odpowiednich warunków badania (fotografia 5).

Badania rozkładu temperatury powietrza w wytypowanych próbkach przeprowadzono w tych temperaturach, które w polskich warunkach klimatycznych występują w sytuacjach ekstremalnych. Ustalono, że skrajne temperatury otoczenia to $55^{\circ} \mathrm{C} \mathrm{i}-25^{\circ} \mathrm{C}$, a jako temperatury powietrza na wejściu do gazomierza przyjęto takie, które odpowiadały temperaturze gruntu na głębokości ułożenia gazociągu w tych okresach ekstremalnych, czyli odpowiednio: dla lata $15^{\circ} \mathrm{C}$, dla zimy $0^{\circ} \mathrm{C}$.
Badania przeprowadzono dla wszystkich obciążeń gazomierza, tzn.: $Q_{\min } ; 3 Q_{\min } ; 0,1 Q_{\max } ; 0,2 Q_{\max } ; 0,4 Q_{\max } ; 0,7 Q_{\max } ; Q_{\max }$.

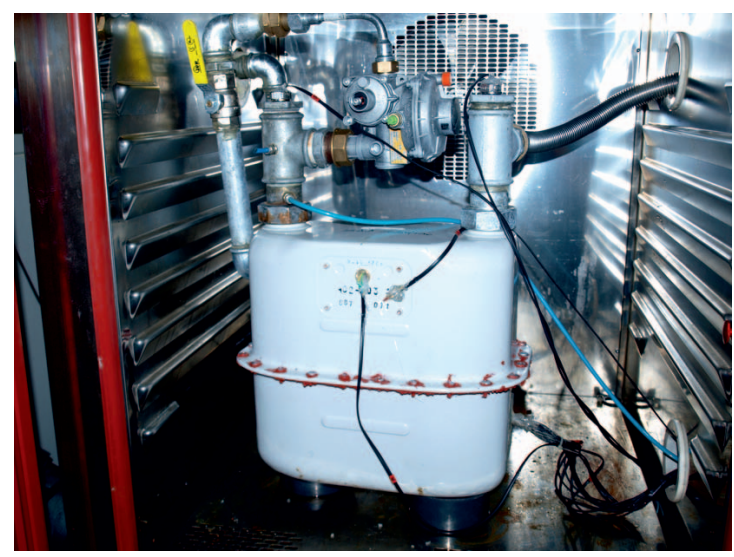

Fot. 5. Badany gazomierz umieszczony w komorze klimatycznej 


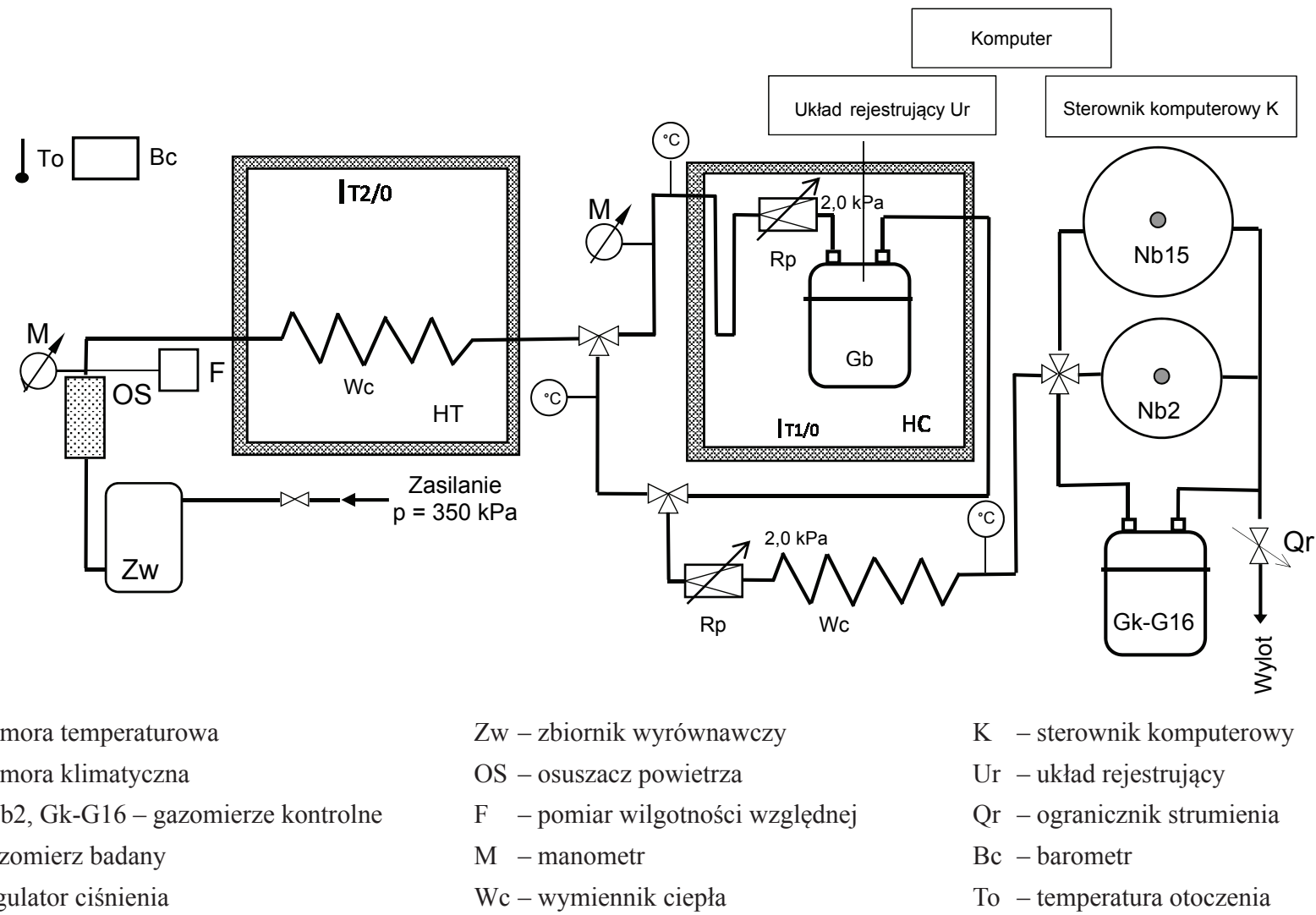

Rys. 3. Schemat stanowiska badawczego

\section{Wyniki badań}

Prowadząc badania szukano odpowiedzi na pytanie, jak skrajne temperatury otoczenia wpływają na temperaturę gazu w przemysłowych gazomierzach miechowych i jak wygląda rozkład temperatury gazu wewnątrz ich obudowy w funkcji temperatury otoczenia, czasu i strumienia objętości powietrza. Wyniki niniejszych badań posłużyły do wyboru optymalnego miejsca pomiaru temperatury gazu w przemysłowych gazomierzach miechowych.

W pierwszej kolejności analizie poddane zostały temperatury związane $\mathrm{z}$ organem pomiarowym gazomierza, czyli w komorze pomiarowej czujniki 10 i 11, w układzie rozrządu czujniki 7, 8 i 9, oraz temperatury w króćcach wejściowym 13 i wyjściowym 14. Dodatkowo w trakcie badań mierzono temperaturę powietrza na wejściu do przyłącza gazowego tuż przed komorą klimatyczną i utrzymywano ją zgodnie z założeniami na poziomie $T_{g}=15^{\circ} \mathrm{C}$ dla $T_{o}=55^{\circ} \mathrm{C}$ i $T_{g}=0^{\circ} \mathrm{C}$ dla $T_{o}=-25^{\circ} \mathrm{C}$.

Analiza wykresów badań dla temperatury otoczenia $T_{o}=55^{\circ} \mathrm{C}$ wskazuje na to, że temperatury powietrza mierzone w układzie pomiarowym gazomierza różnią się od siebie, przy czym różnice te uwidaczniają się wraz ze wzrostem obciążenia i czasu przepływu powietrza. Największe rozbieżności w tych temperaturach obserwowane są dla obciążenia maksymalnego $Q_{\max }$.
Krzywe 9 i 10 reprezentują temperaturę powietrza mierzoną pod prawym lustrem komory pomiarowej A i w jednej przegrodzie tej komory (od strony obudowy gazomierza), natomiast krzywe 7 i 11 przedstawiają temperaturę mierzoną pod lewym lustrem komory A i w drugiej części tej komory (od strony wewnętrznej gazomierza).

Różnice pomiędzy temperaturami 7 i 9 dla próbki nr 1 nie przekraczają $1,8^{\circ} \mathrm{C}$, dla stanu ustalonej wymiany ciepła. Dla próbki nr 2 różnice są pomijalne $-0,3^{\circ} \mathrm{C}$, a dla próbki nr 3 sięgają aż $3,5^{\circ} \mathrm{C}$ przy strumieniu $10 \mathrm{~m}^{3} / \mathrm{h}$.

Różnice rzędu $1,2^{\circ} \mathrm{C}(\mathrm{G} 16), 1,1^{\circ} \mathrm{C}(\mathrm{G} 10), 0,7^{\circ} \mathrm{C}(\mathrm{G} 6)$ widoczne są w przebiegu temperatur 10 i 11 mierzonych w dwóch częściach komory pomiarowej A gazomierza. Wyższa temperatura 10 odpowiada tej części komory, która przylega do obudowy gazomierza, dlatego można wnioskować, iż oddziaływanie temperatury otoczenia $\mathrm{w}$ tym miejscu jest większe.

Szczegółowo przeanalizowano również przebieg temperatury na wyjściu z komory pomiarowej-czujnik 8 , a także w króćcu wyjściowym gazomierza - czujnik 14. Dla każdej z próbek obie temperatury mają inny charakter. Dla próbki G10 różnice pomiędzy krzywymi wynoszą maksymalnie $0,7^{\circ} \mathrm{C}$. Dla próbek $\mathrm{G} 16$ i G6 to różnice wysokości $1,4^{\circ} \mathrm{C}$ i $2,3^{\circ} \mathrm{C}$. 
Analiza przebiegu temperatury powietrza wchodzącego do przyłącza gazowego, a następnie do gazomierza - czujnik 13, wskazuje na to, że także w przypadku przyłącza gazowego następuje proces nieustalonej wymiany ciepła. Przy strumieniach maksymalnych każdej z próbek wymiana ciepła na stalowym przyłączu o długości jednego metra jest na tyle duża, że z temperatury $15^{\circ} \mathrm{C}$ na jego wlocie powietrze ogrzewa się do $31,2^{\circ} \mathrm{C}(\mathrm{G} 16), 36,6^{\circ} \mathrm{C}(\mathrm{G} 10), 39,8^{\circ} \mathrm{C}(\mathrm{G} 6)$ na króćcu wlotowym do gazomierza.

Proces wymiany ciepła po zatrzymaniu przepływu powietrza przez gazomierz ukazuje znaczne różnice (w stanie nieustalonym) pomiędzy temperaturą $\mathrm{w}$ gazomierzu 8 a temperaturą w króćcu wyjściowym 14 , które sięgają nawet do $6,8^{\circ} \mathrm{C}(\mathrm{G} 16), 4,8^{\circ} \mathrm{C}(\mathrm{G} 10), 4,9^{\circ} \mathrm{C}(\mathrm{G} 6)$. Czujnik 8 zainstalowano w rozrządzie gazomierza, gdzie konwekcja była utrudniona, co wpływało na dłuższy czas stabilizacji temperatury w tym miejscu. Dlatego jeśli w trakcie wzrostu temperatury rozpocząłby się przepływ gazu przez gazomierz, to czujnik 14 w króćcu wyjściowym zmierzyłby wyższą temperaturę medium od tej rzeczywistej panującej w komorze pomiarowej. Nie można zatem stosować temperatury mierzo- nej w króćcu wyjściowym jako temperatury reprezentatywnej do obliczeń rozliczeniowych gazu. Należy przyjmować inną bardziej miarodajną temperaturę, np. $\mathrm{nr} 8$.

Analiza pozostałych wykresów dla $T_{o}=55^{\circ} \mathrm{C}$ potwierdza wcześniejsze wnioski, z których wynika, że wraz ze wzrostem przepływu gazu spada temperatura w gazomierzu.

Najwyższe temperatury zostały zmierzone czujnikiem 15 oraz 12, co wiąże się z faktem, że czujniki te nie posiadają żadnego bezpośredniego kontaktu z wpływającym do gazomierza powietrzem, lecz jedynie kontakt pośredni, poprzez obudowę gazomierza i tuleję sprzęgła magnetycznego. W tych miejscach w gazomierzach miechowych z kompensacją temperatury zostały umieszczone czujniki do pomiaru temperatury, na podstawie której wyznacza się objętość rozliczeniową gazu. Należy stwierdzić, iż dla przemysłowych gazomierzy takie rozwiązanie obarczone jest błędami i trzeba dążyć do jego ulepszenia.

Rysunki 4-6 przedstawiają wyniki badań procesu wymiany ciepła w badanych próbkach dla warunków temperatury otoczenia $T_{o}=55^{\circ} \mathrm{C}$ i temperatury wejściowej do przyłącza gazowego $T_{g}=15^{\circ} \mathrm{C}$.

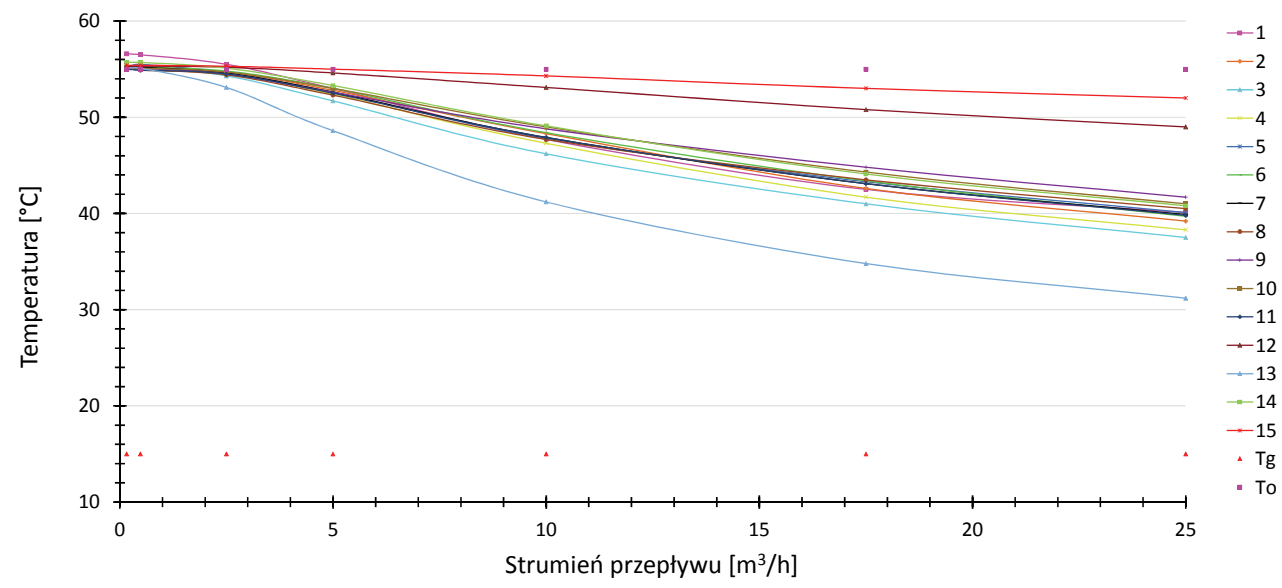

Rys. 4. Rozkład temperatury gazu w przemysłowym gazomierzu miechowym (obiekt nr 1-G16) przy temperaturze otoczenia $T=55^{\circ} \mathrm{C}$ w zależności od strumienia przepływu - stan ustalony

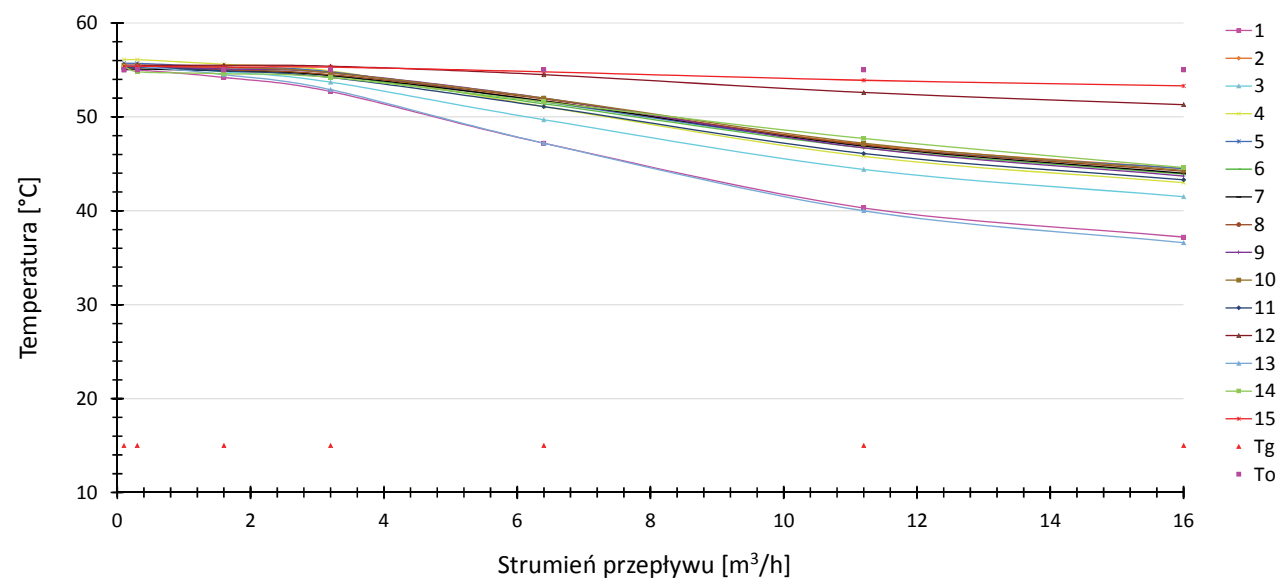

Rys. 5. Rozkład temperatury gazu w przemysłowym gazomierzu miechowym (obiekt nr 2 - G10) przy temperaturze otoczenia $T=55^{\circ} \mathrm{C}$ w zależności od strumienia przepływu - stan ustalony 


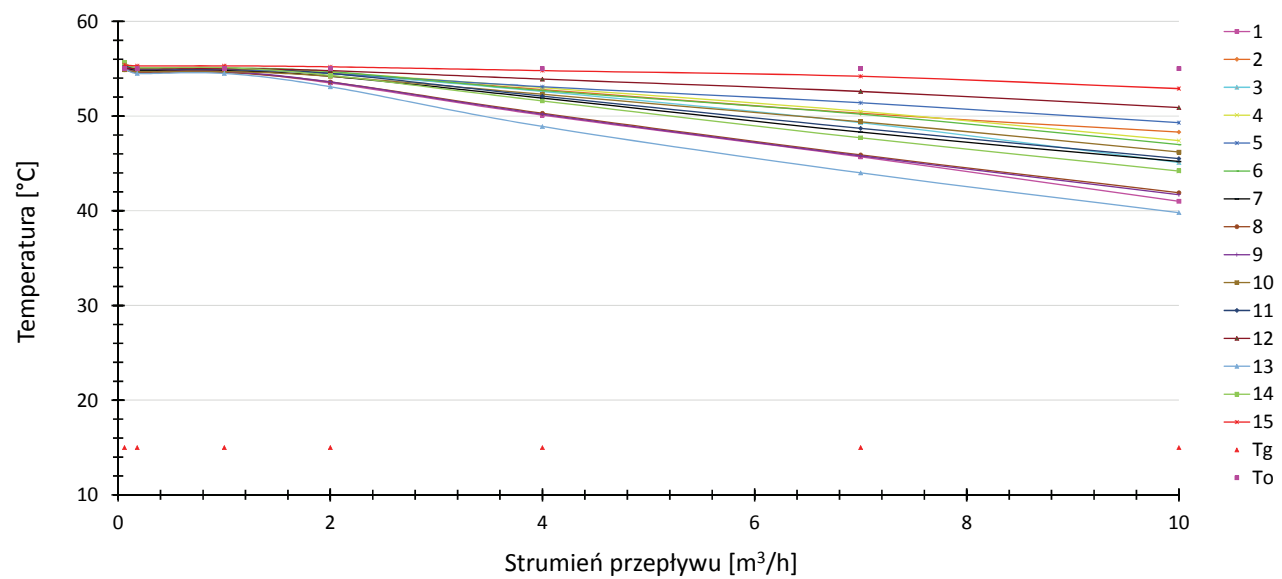

Rys. 6. Rozkład temperatury gazu w przemysłowym gazomierzu miechowym (obiekt nr 3 - G6) przy temperaturze otoczenia $T=55^{\circ} \mathrm{C}$ w zależności od strumienia przepływu - stan ustalony

Rysunki 7-9 przedstawiają wyniki badań procesu wymiany ciepła w badanych próbkach dla warunków temperatury otoczenia $T_{o}=-25^{\circ} \mathrm{C}$ i temperatury wejściowej do przyłącza gazowego $T_{g}=0^{\circ} \mathrm{C}$. Analiza niniejszych wykresów potwierdza wcześniejsze wnioski odnośnie przebiegu wymiany ciepła, lecz zmianie uległ kierunek przepływu ciepła. Zmie- niła się także skuteczność wymiany ciepła, tzn. zmniejszyły się różnice pomiędzy temperaturą otoczenia a temperatura przepływającego powietrza.

To, jak ważna jest budowa poszczególnych gazomierzy dla procesu wymiany ciepła, widać doskonale na przykładzie dwóch próbek G16 i G6, których zakres pomiarowy

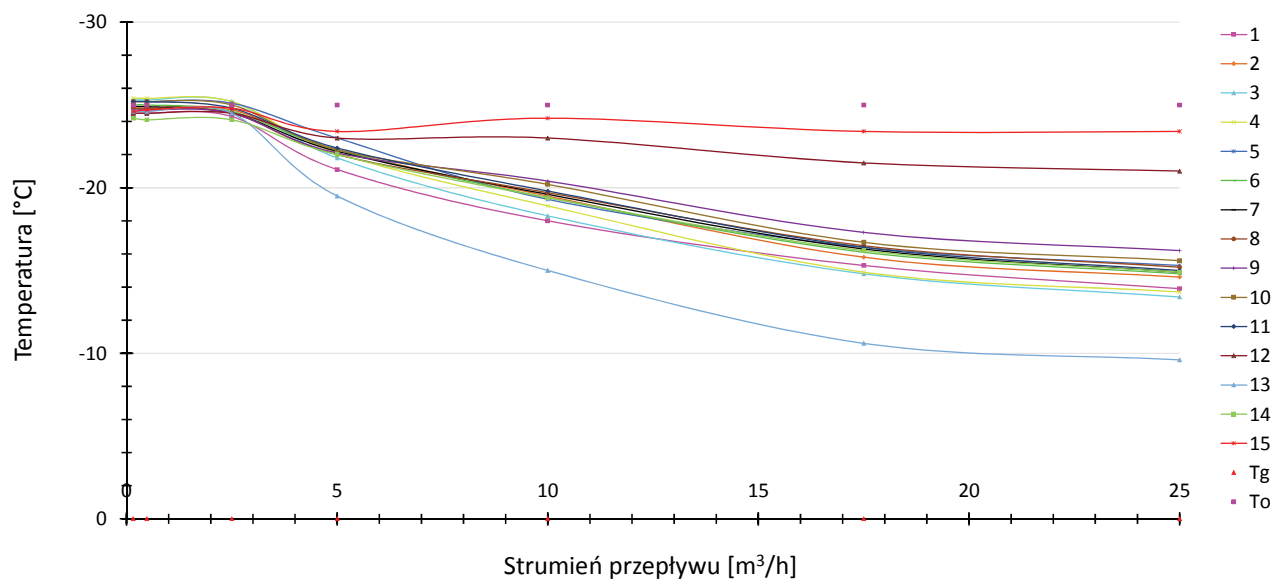

Rys. 7. Rozkład temperatury gazu w przemysłowym gazomierzu miechowym (obiekt nr 1-G16) przy temperaturze otoczenia $T=-25^{\circ} \mathrm{C}$ w zależności od strumienia przepływu - stan ustalony

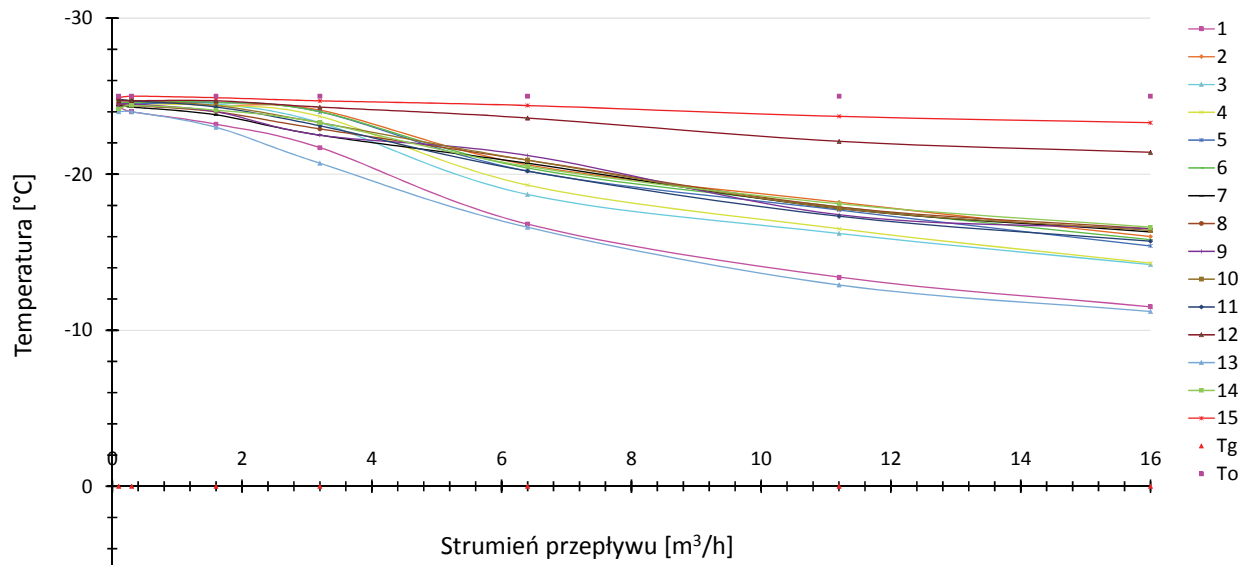

Rys. 8. Rozkład temperatury gazu w przemysłowym gazomierzu miechowym (obiekt nr 2 - G10) przy temperaturze otoczenia $T=-25^{\circ} \mathrm{C}$ w zależności od strumienia przepływu - stan ustalony 


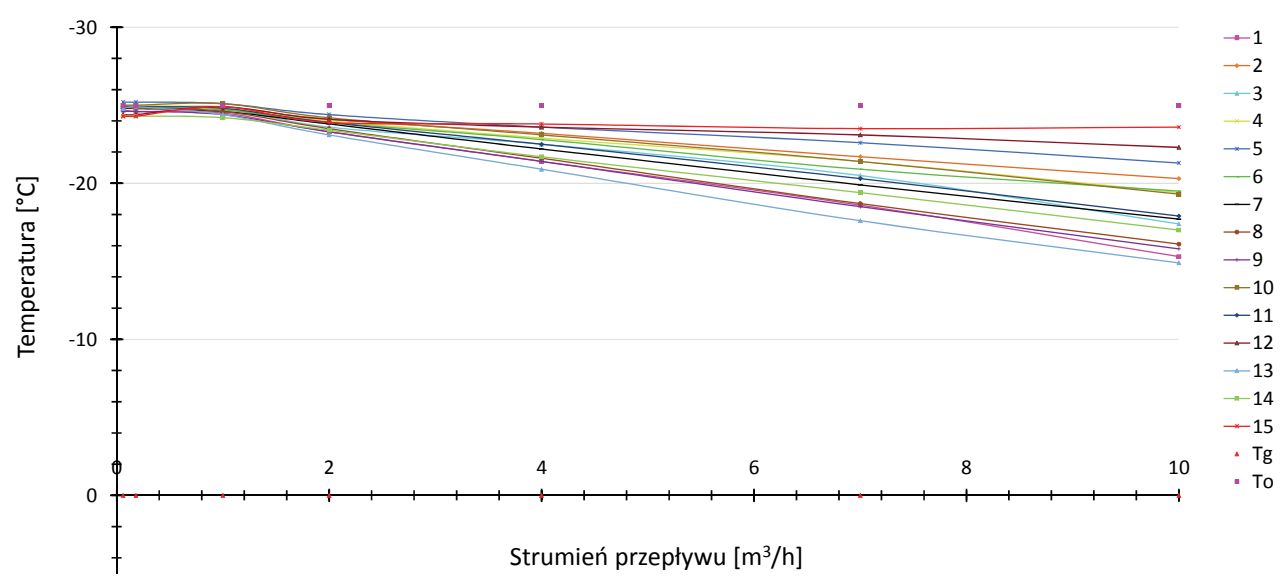

Rys. 9. Rozkład temperatury gazu w przemysłowym gazomierzu miechowym (obiekt nr 3 - G6) przy temperaturze otoczenia $T=-25^{\circ} \mathrm{C}$ w zależności od strumienia przepływu - stan ustalony

obejmuje ten sam strumień $10 \mathrm{~m}^{3} / \mathrm{h}$. Przy czym dla próbki G16 jest to środkowa część zakresu pomiarowego, tj. strumień $0,4 Q_{\max }$, natomiast dla próbki G6 jest to strumień maksymalny. Różnica przebiegu temperatur czujnika nr 8 (temperatura na wyjściu z komór pomiarowych) dla tych dwóch próbek wyniosła: $5,8^{\circ} \mathrm{C}$ - przy temperaturze otoczenia $55^{\circ} \mathrm{C}$; $3,6^{\circ} \mathrm{C}$ - przy temperaturze otoczenia $-25^{\circ} \mathrm{C}$.

$\mathrm{W}$ celu lepszego zobrazowania rozkładu temperatury gazu w przemysłowych gazomierzach miechowym wykonano pomiar termograficzny przy użyciu kamery termowizyjnej. Metoda pomiaru temperatury za pomocą kamery termowizyjnej została dokładnie opisana $[3,4,9,10,14,18$, 19, 22, 23]. Warunkiem koniecznym wykonania poprawnego pomiaru termograficznego jest widoczność mierzonego obiektu [2].

Badanie przeprowadzono na gazomierzu miechowym $\mathrm{G} 10 \mathrm{w}$ temperaturze otoczenia $T_{o}=20^{\circ} \mathrm{C}$, przy jednoczesnym przepuszczaniu przez gazomierz powietrza o strumieniu $16 \mathrm{~m}^{3} / \mathrm{h}$ i temperaturze $T_{g}=15^{\circ} \mathrm{C}$. Ponadto w trakcie wykonywania zdjęć termowizyjnych prowadzono pomiar temperatury powietrza w badanym gazomierzu przy użyciu układu rejestrującego. Zdjęcie 6 obrazuje stan ustabilizowany układu, gdzie przyłącze, reduktor oraz badany gazomierz emitują tę samą wartość promieniowania cieplnego.

Zarówno czujniki temperatury (rysunek 10), jak i kamera termowizyjna (fotografia 7) zarejestrowały w pierwszym etapie zmiany temperatury na czujnikach 13, 1, 3 (zgodnie ze schematem rozmieszczenia czujników - rysunek 1). Proces wymiany ciepła pomiędzy otoczeniem gazomierza a gazem płynącym w jego wnętrzu, zgodnie $\mathrm{z}$ analizą danych z rysunku 10, przebiegał stopniowo w kierunku środka i prawej strony obudowy gazomierza (fotografia 7). Po czterech minutach od uruchomienia przepływu zakończył się pierwszy etap procesu wymiany ciepła chwilowym stanem ustalonym. Od drugiej minuty można zaobserwować rozpoczę- cie kolejnego etapu stabilizacji, poprzez pogłębienie różnicy temperatur, który postępował aż do uzyskania całkowitego stanu ustalonego.

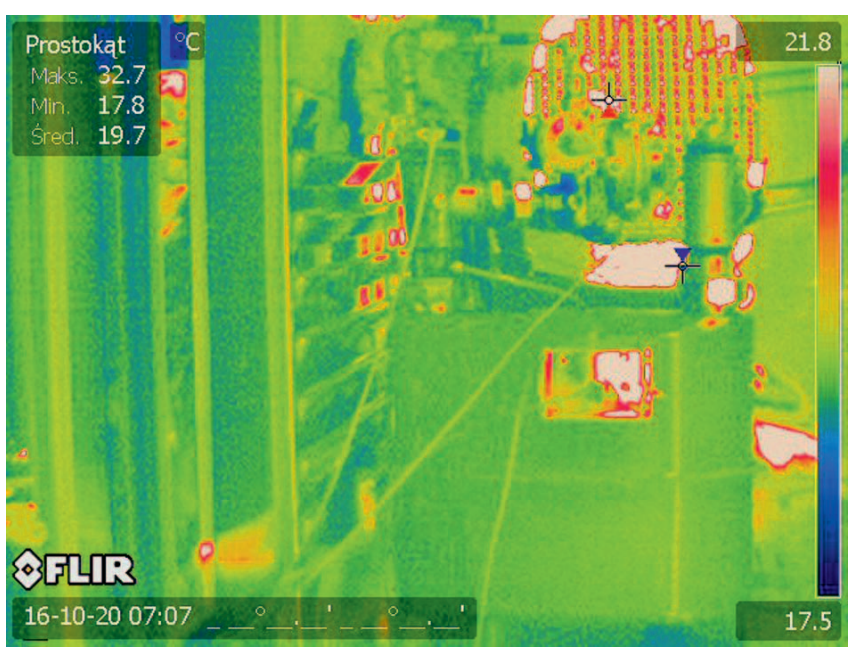

Fot. 6. Pomiar termowizyjny przemysłowego gazomierza miechowego G10 (obiekt nr 2)

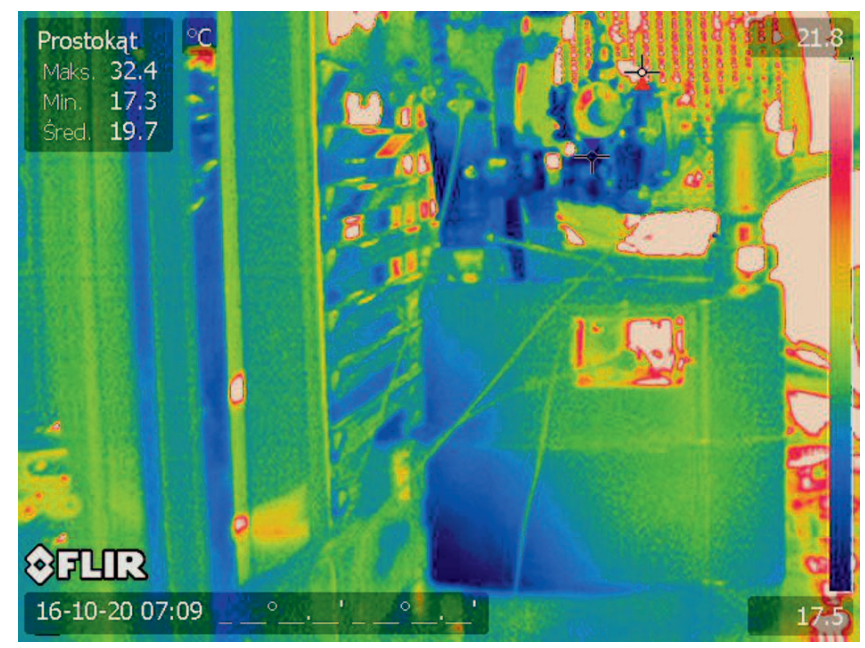

Fot. 7. Pomiar termowizyjny przemysłowego gazomierza miechowego G10 (obiekt nr 2) 


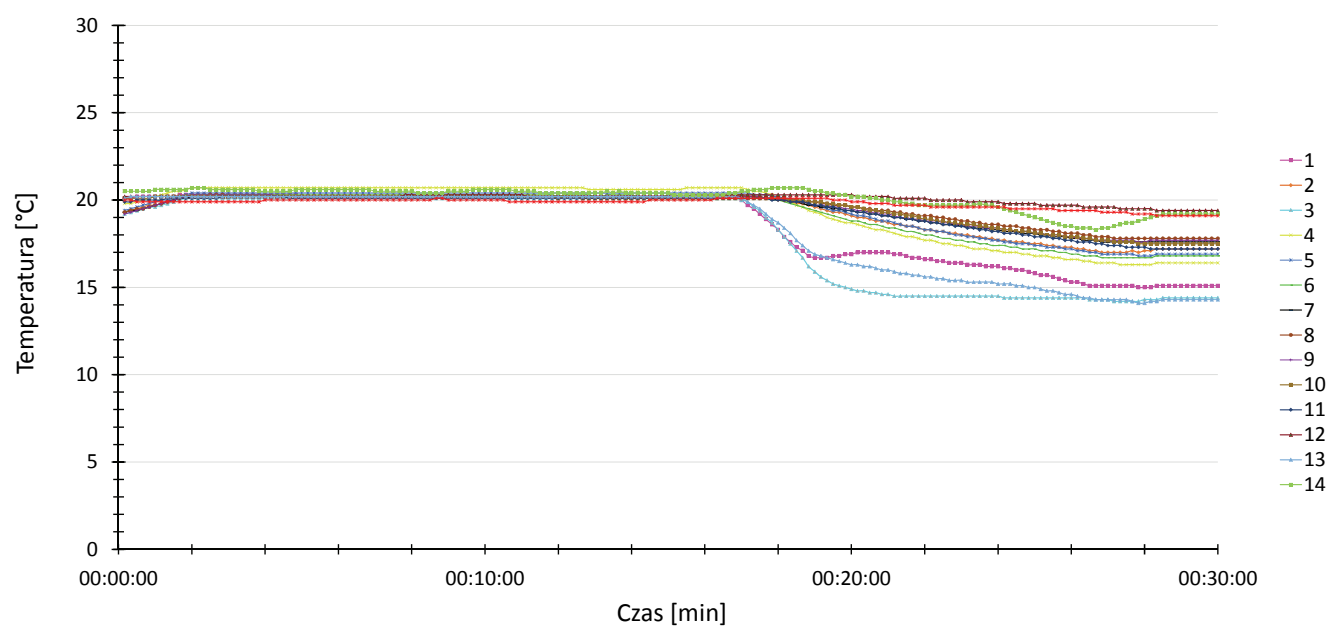

Rys. 10. Przebieg temperatury powietrza w gazomierzu G10 (obiekt $\mathrm{nr} 2$ ), $T_{o}=20^{\circ} \mathrm{C}, T_{g}=15^{\circ} \mathrm{C}, Q=16 \mathrm{~m}^{3} / \mathrm{h}$

Uzyskane wyniki poddano dodatkowej analizie, polegającej na określeniu zależności pomiędzy powierzchnią (obudowy gazomierza) wymiany ciepła i objętością cykliczną a otrzymanymi wartościami temperatur. W tym celu wyznaczono liczbę cykli wykonanych przez mechanizm pomiarowy badanych próbek w ciągu godziny przy każdym ze strumieni objętości z ich zakresów pomiarowych.

$$
Z=\frac{1000 \cdot t \cdot Q}{V_{c}}
$$

gdzie:

$Z$ - liczba cykli układu pomiarowego [-],

$t$ - czas [h],

$Q$ - strumień objętości $\left[\mathrm{m}^{3} / \mathrm{h}\right]$,

$V_{c}$ - objętość cykliczna $\left[\mathrm{dm}^{3}\right]$.

Na podstawie otrzymanych wyników określono czas jednego cyklu przy danym strumieniu, zarazem uzyskano informacje na temat czasu przebywania danej objętości gazu wewnątrz gazomierza, na którą wpływa temperatura otoczenia (tablica 3).
Z przeprowadzonej analizy wynika, że dla nominalnych strumieni objętości w zakresie $0,1 Q_{\max } \div Q_{\text {max }}$, pomimo znacznych różnic w powierzchniach obudowy oraz objętościach cyklicznych, czasy przebywania gazu w układach pomiarowych dla próbek nr 1 (G16) i 3 (G6) są takie same. Niemniej jednak porównanie należało przeprowadzić przy strumieniach, których wartości są równe dla każdej z badanych próbek.

Jedynym strumieniem o tych samych wartościach był strumień $10 \mathrm{~m}^{3} / \mathrm{h}$ dla próbek G16 $\left(0,4 Q_{\max }\right)$ i G6 $\left(Q_{\max }\right)$. Czas przebywania w układzie pomiarowym objętości gazu odpowiadającej objętości cyklicznej przy strumieniu $10 \mathrm{~m}^{3} / \mathrm{h}$ dla próbki G16 (1,8 sekundy) był 2,5 razy dłuższy niż dla próbki G6 ( 0,72 sekundy). Biorąc pod uwagę powyższe informacje oraz otrzymane wartości temperatur na poszczególnych czujnikach, należy stwierdzić, iż proces wymiany ciepła dla gazomierza G16 okazał się skuteczniejszy. Tym samym potwierdzono, że proces wymiany ciepła pomiędzy otoczeniem przemysłowych gazomierzy miechowych a gazem płynącym w ich wnętrzu jest silnie zależny od powierzchni wymiany ciepła, jaką jest obudowa, oraz od objętości cyklicznej.

Tablica 3. Zestawienie cykli pomiarowych badanych gazomierzy w odniesieniu do strumieni objętości

\begin{tabular}{|c|c|c|c|c|c|c|}
\hline \multirow{2}{*}{$Q\left[\mathrm{~m}^{3} / \mathrm{h}\right]$} & \multicolumn{2}{|c|}{$\mathrm{G} 6\left(V_{c}=2 \mathrm{dm}^{3}\right)$} & \multicolumn{2}{c|}{$\mathrm{G} 10\left(V_{c}=5,6 \mathrm{dm}^{3}\right)$} & \multicolumn{2}{c|}{$\mathrm{G} 16\left(V_{c}=6 \mathrm{dm}^{3}\right)$} \\
\cline { 2 - 7 } & $Z / \mathrm{h}$ & czas $1 Z[\mathrm{~s}]$ & $Z / \mathrm{h}$ & $\mathrm{czas} 1 Z[\mathrm{~s}]$ & \multicolumn{1}{c|}{$Z / \mathrm{h}$} & $\mathrm{czas} 1 Z[\mathrm{~s}]$ \\
\hline$Q_{\max }$ & 5000 & 0,72 & 2857,1 & 1,35 & 5000 & 0,72 \\
\hline $0,7 Q_{\max }$ & 3500 & 1,03 & 2000,0 & 1,93 & 3500 & 1,03 \\
\hline $0,4 Q_{\max }$ & 2000 & 1,80 & 1142,9 & 3,375 & 2000 & 1,80 \\
\hline $0,2 Q_{\max }$ & 1000 & 3,60 & 571,4 & 6,75 & 1000 & 3,60 \\
\hline $0,1 Q_{\max }$ & 500 & 7,20 & 285,7 & 13,50 & 500 & 7,20 \\
\hline $3 Q_{\min }$ & 90 & 40,00 & 53,6 & 72,00 & 96 & 37,50 \\
\hline$Q_{\min }$ & 30 & 120,00 & 17,9 & 216,00 & 32 & 112,50 \\
\hline
\end{tabular}




\section{Wnioski}

1. Uzyskane wyniki badań potwierdzają, że proces wymiany ciepła w przemysłowym gazomierzu miechowym zależny jest od temperatury otoczenia, temperatury gazu na wlocie do gazomierza, strumienia objętości przepływającego gazu, parametrów fizycznych tego gazu oraz od powierzchni obudowy i objętości cyklicznej gazomierza. W ramach pracy ustalono, że kolejnym czynnikiem wpływającym na temperaturę $\mathrm{w}$ gazomierzu jest rodzaj zastosowanego przyłącza gazowego, a przede wszystkim długość odcinka wychodzącego spod powierzchni terenu, średnica czy też grubość ścianki materiału. Zagadnienie nieustalonej wymiany ciepła na przyłączu gazowym jest na tyle istotne, że należy je dokładnie przebadać $\mathrm{w}$ ramach osobnej pracy, $\mathrm{z}$ uwzględnieniem różnych długości i średnic.

2. Najwyższa temperatura została zmierzona czujnikiem 15 (powierzchnia obudowy gazomierza pod jego liczydłem) oraz 12 (w tulei sprzęgła magnetycznego), co wiąże się $\mathrm{z}$ faktem, że czujniki te nie posiadają żadnego bezpośredniego kontaktu $\mathrm{z}$ wpływającym do gazomierza powietrzem, lecz jedynie kontakt pośredni poprzez obudowę gazomierza i tuleję sprzęgła magnetycznego. W tych miejscach w gazomierzach miechowych z kompensacją temperatury zostały umieszczone czujniki do pomiaru temperatury, na podstawie której wyznacza się objętość rozliczeniową gazu. Dlatego należy stwierdzić, iż dla przemysłowych gazomierzy miechowych takie rozwiązanie obarczone jest błędami i należy dążyć do jego poprawy.

3. Potwierdzono, że dla przemysłowych gazomierzy miechowych proces wymiany ciepła pomiędzy otoczeniem gazomierza a gazem płynącym $\mathrm{w}$ jego wnętrzu jest procesem na tyle złożonym, że niemożliwe jest stosowanie uproszczeń w postaci uniwersalnych współczynników korekcyjnych temperatury gazu do rozliczeń objętości zużytego gazu.

Szczegółowa analiza przebiegu temperatur w gazomierzu potwierdziła również wyniki dotychczasowych badań, zgodnie z którymi wyjście z komór pomiarowych na rozrządzie układu pomiarowego gazomierza jest reprezentatywnym miejscem do pomiaru temperatury gazu w celach rozliczeniowych objętości zużytego gazu. Dlatego głównym zaleceniem dotyczącym układów rozliczeniowych wykorzystujących przemysłowe gazomierze miechowe, mającym przynieść najdokładniejsze pomiary zużycia medium, jest stosowanie przeliczników objętości gazu z pomiarem temperatury na wyjściu z komór pomiarowych. Niemniej jednak ze względu na utrudnienia techniczne i związane $\mathrm{z}$ tym koszty finansowe, w wyniku seryjnego montażu w tym miejscu czujnika temperatury, wytypowano króciec wyjściowy gazomierza jako lokalizację zastępczą do pomiaru temperatury „rozliczeniowej”. Podobieństwo przebiegu krzywych tych dwóch temperatur w trakcie badań przy cyklu z przepływem było zadowalające. Proces wymiany ciepła po zatrzymaniu przepływu powietrza przez gazomierz ukazuje znaczne różnice (w stanie nieustalonym) pomiędzy temperaturą na wyjściu z komór pomiarowych a temperaturą w króćcu wyjściowym, które sięgają nawet do $8,2^{\circ} \mathrm{C}$ dla badanych przypadków. W rozrządzie gazomierza zjawisko konwekcji jest utrudnione, co wpływa na dłuższy czas stabilizacji temperatury w tym miejscu. Jeżeli w trakcie odbudowy temperatury rozpocząłby się przepływ gazu przez gazomierz, to czujnik w króćcu wyjściowym zmierzyłby wyższą temperaturę medium od tej rzeczywistej panującej w komorze pomiarowej. Wobec tego zasadnym jest przeprowadzenie kolejnych badań wyznaczania rozkładu temperatury gazu w przemysłowych gazomierzach miechowych obejmujących różne wielkości i typy tych gazomierzy, w celu lepszego poznania tak złożonego procesu.

4. Nie należy prowadzić starań mających na celu wyznaczenie współczynników korekcyjnych dla każdego gazomierza z osobna, lecz dążyć do opracowania korelacji pomiędzy temperaturą na wyjściu z komór pomiarowych i temperaturą w króćcu wyjściowym.

Prosimy cytować jako: Nafta-Gaz 2017, nr 5, s. 321-331, DOI: 10.18668/NG.2017.05.04

Artykuł nadesłano do Redakcji 22.12.2016 r. Zatwierdzono do druku 16.03.2017 r.

Artykuł powstał na podstawie pracy statutowej pt. Wpływ warunków temperaturowych na wymianę ciepła w przemyslowych gazomierzach miechowych - praca INiG - PIB na zlecenie MNiSW; nr zlecenia: 0056/GM/16, nr archiwalny: DK-4100-56/16.

\section{Literatura}

[1] Analiza procesów wymiany ciepła $w$ gazomierzach miechowych. Praca IGNiG, zlec. wew. 46/GM, 2000.

[2] Basiura M.: Zastosowanie kamery termowizyjnej w procesie badania prototypów urządzeń. Nafta-Gaz 2014, nr 5 , s. $320-324$.
[3] Basiura M., Rataj M.: Przeglad i adaptacja procedur badawczych z zakresu pomiarów termowizyjnych. Dokumentacja wewnętrzna INiG, 2012.

[4] Basiura M., Rataj M.: Wykrywanie nieszczelności winstalacjach i urzadzeniach gazowych za pomoca metody obserwacji w paśmie 
podczerwieni. Gaz, Woda i Technika Sanitarna 2013, nr 11, s. 426-429.

[5] Bertke H.: Entwicklung und Prüfung von temperaturumwertenden Gaszählern. Deutscher Verein von Gas- und Wasserfachmännern (DVGW) 1993.

[6] Dudek A.: Wymagania instalacyjne dla gazomierzy. WarunkiTechniczne.PL 2015, nr 5 [11], s. 53-55.

[7] Hlinčík T., Koza V.: Temperature field inside the diaphragm gas meter. Paliva 8, 2016, 1, s. 39-44.

[8] Hlinčík T., Koza V.: Vliv teploty a průtoku na údaj membránových plynomérů bez teplotni kompenzace. Paliva 4, 2012, 4, s. $111-116$.

[9] Infrared Training Center, Termografia - poziom 1. Podręcznik szkoleniowy, wersja polska.

[10] Instrukcja obsługi FLIR GF series Publ. No. T559460 Rev. a445, Polish (PL), 25.03.2010.

[11] Jasiński G.: Kierunki działań PSG Sp. z o.o. w zakresie uktadów pomiarowych z gazomierzami miechowymi. Sympozjum TOP-GAZ VII Edycja „Technika opomiarowania gazu dziś i jutro", Rogów 2015.

[12] Jaworski J.: Badania odporności gazomierzy miechowych na temperature otoczenia. Nafta-Gaz 1999, nr 8, s. 466-471.

[13] Jaworski J.: Wplyw temperatury otoczenia na prace gazomierzy miechowych $w$ aspekcie krajowych warunków klimatyczno-technicznych. Rozprawa doktorska, Akademia Górniczo-Hutnicza, Kraków 2004.

[14] Knapek D.: Termowizja - wszystko co musisz wiedzieć, aby prawidtowo wykonać pomiar. Materiały ze szkolenia, EC Training Center.

[15] Mobers L.P.H.: Über die Meßgenauigkeit von Haushaltsgaszählern in Holland. Gwf Gas-Erdgas 1988, vol. 129, nr 2.
[16] Nath B.: Temperaturverhalten von Industriebalgengaszählern. Gwf Gas-Erdgas 1995, vol. 136, nr 2.

[17] Opracowanie modelu wymiany ciepła na drodze przeptywu gazu od przyłacza gazowego do gazomierza miechowego. Praca IGNiG, zlec. wew. 56/GM/2002.

[18] Rutkowski P.: Pomiary termowizyjne w energetyce. Materiały ze szkolenia, EC Training Center.

[19] Standard for Infrared Inspection of Electrical Systems \& Rotating Equipment. Edycja 2008.

[20] Wagner-Staszewska T.: Domowe gazomierze ultradźwiękowe. Nafta-Gaz 2000, nr 5, s. 288-299.

[21] Wagner-Staszewska T., Jaworski J.: Wplyw temperatury otoczenia na nierozliczone ilości gazu u indywidualnych odbiorców gazu. Nafta-Gaz 2001, nr 11, s. 620-626.

\section{Akty prawne i normatywne}

[22] Norma ISO 18434-1:2008 Condition monitoring and diagnostics of machines - Thermography - Part 1: General procedures.

[23] Norma PN-EN 13187:2001 Właściwości cieplne budynków - Jakościowa detekcja wad cieplnych w obudowie budynku-Metoda podczerwieni.

[24] Obwieszczenie Ministra Infrastruktury i Rozwoju z dnia 17 lipca 2015 r. w sprawie ogłoszenia jednolitego tekstu rozporządzenia Ministra Infrastruktury w sprawie warunków technicznych, jakim powinny odpowiadać budynki i ich usytuowanie (Dz. U. z 2015 r. nr 0, poz. 1422).

[25] ST-IGG-1101:2011 Połaczenie PE/stal dla gazu ziemnego wraz ze stalowymi elementami do właczeń oraz elementami do przyłączeń.

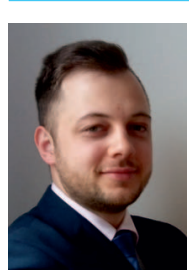

Mgr inż. Adrian DUDEK

Specjalista inżynieryjno-techniczny w Zakładzie

Metrologii Przepływów

Instytut Nafty i Gazu - Państwowy Instytut Badawczy

ul. Lubicz 25 A

31-503 Kraków

E-mail: adrian.dudek@inig.pl

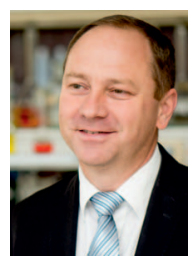

Dr inż. Jacek JAWORSKI

Adiunkt; zastępca Dyrektora ds. Gazownictwa.

Instytut Nafty i Gazu - Państwowy Instytut Badawczy ul. Lubicz 25 A

31-503 Kraków

E-mail: jacek.jaworski@inig.pl 